\title{
THE MOST RECENT ANTIBIOTIC AGENTS
}

\author{
By George Brownlee, Ph.D., D.Sc. \\ Department of Pharmacology, University of London, King's College
}

The forfeit which medicine pays for the fruitful discovery of antibacterial chemotherapy is the embarrassment of riches. The corrective, should it prove necessary, is provided by recalling to mind the state of affairs which existed before Domagk's (1935) discovery of the chemotherapeutic activity of prontosil rubrum against infections due to Streptococcus pyogenes. So little success had resulted from attempts to apply the classical chemotherapy of protozoa and spirochaetes to bacteria that in many quarters failure was presumed to be inevitable. Indeed, the slow development which had characterized the use of mepacrine, claimed by Kikuth in 1932 to be a useful drug for the treatment of malaria, might well have been duplicated with prontosil rubrum but for the careful work of Colebrook and Kenny (1935) in puerperal sepsis. The significance of this discovery could not be underestimated, and an explosive burst of energy resulted. Thus, by 1940, with the discovery of the substituted sulphonamides, pneumococci had been brought within the scope of action and the range widened to include staphylococci. The stage was now set.

Interest in mutual antagonism between microorganisms is as old as Pasteur's fundamental studies, but the many researches undertaken today in this field derived their impetus from the demonstration of the chemotherapeutic nature of penicillin by Florey and his collaborators (Chain, Florey, Gardner, Heatley, Jennings, Orr-Ewings and Sanders, 1940). These observations, in turn, started with the inhibitory action of the mould contaminant observed by Fleming (r929). The singular freedom from toxicity of even grossly impure samples, when taken together with its catholic range of antibacterial and antispirochaetal activity, distinguishes it as the most remarkable chemotherapeutic agent ever discovered.

The methods which were developed for the selection of high-yielding strains of penicillium notatum, and those which emerged for the extraction and purification of the antibiotic provided a pattern which was to be followed and duplicated with bewildering frequency. The effect was to broaden the range of pathogens brought within the scope of chemotherapy and to increase the efficiency of known examples.
The result has not been an unalloyed delight to the physician, since the claims of alternative chemotherapeutic antibiotics are inevitably pressed before adequate therapeutic comparison has yet established the final place of their predecessors. Nevertheless the discipline of adequate therapeutic comparison remains the minimal standard by which a final assessment may be made. In this way the established position of sulphonamides, penicillin and streptomycin is subject to constant review; and in the same way must the challenge of aureomycin, chloramphenicol and terramycin be proved. Thus it remains the duty of the physician to weigh and balance the claims of new discoveries against those of well-tried agents, as it is also the duty of the pharmacologist to advance the claims of others. The minimal pharmacological requirements which are the essential prerequisite to clinical trial are now well understood.

At this stage of our review it is pertinent to enquire whether the experiences which have guided the choice of currently accepted antibiotics furnish any clue to current and future claimants. Let us turn first to this aspect.

\section{Factors Affecting the Choice of New Anti- biotic Agents}

I. The antibiotic affects pathogens higherto insusceptible to chemotherapy. A new antibiotic with an adequate therapeutic index* effective in diseases caused by viruses, in infections caused by some gram-negative rods, such as proteus, in some protozoal infections, such as hepatic amoebiasis, will be pressed into future service.

2. The antibiotic affects pathogens susceptible to existing chemotherapy but is less toxic. An equally effective agent which proved less toxic than streptomycin to the eighth nerve would be expected to displace its use in tuberculosis. Similarly an equally effective agent with a wider margin of safety would be expected to displace polymyxin

$$
\begin{aligned}
\text { *Therapeutic Index } & =\frac{\text { Average Lethal Dose }}{\text { Minimal Effective Dose }} \\
& =\frac{\text { LD }_{50}}{\text { M.E.D. }}
\end{aligned}
$$


$\mathrm{B}$ or $\mathrm{E}$ in meningitis of Haemophylus influenzae or Pseudomonas pyocyanea origin.

3. The antibiotic is equally effective yet is less prone to facilitate emergence of resistant strains. The rapidity with which organisms develop resistance to streptomycin in clinical use constitutes its greatest disadvantage, and may be expected to condition its replacement.

Certain members of the gas-producing anaerobes and the causal organism of tuberculosis are notable omissions from paragraph $\mathrm{I}$. It is probably not to be expected that the discovery of an intrinsically more efficient antibiotic would alter the present day concepts of management of these infections. It seems that the pathogenesis of the disease dictates its course and the elimination of the causal organism by antibacterial action may not remove the immediately toxic factor. If we turn to the experiences given by tests of comparable efficiency of antibiotics and other chemotherapeutic agents in controlled animal experiments on a variety of genera, the underlying reasons begin to appear.

In their more usual forms the tests are designed strictly as biological standardizations; that is to say, as an assay in which one drug, posing as a standard, is compared with another. The endpoint is a convenient biochemical reaction caused by the parasite. They are therefore analogous to the standardization of insulin or of diphtheria toxin. They are not analogous to the clinical treatment of diabetes or diphtheria and, of course, they resemble only faintly the clinical chemotherapy of tuberculosis. Nevertheless, tests of this kind supply much additional evidence; it is only when we misuse this information that we are led astray. This often happens.

\section{Animal Tests}

The amount of information to be extracted from an animal test is restricted by its design. A study of the development of chemotherapy reveals the reasons for modelling tests upon those which proved successful in the development, first of protozoal and then of gram-positive and, later, gram-negative bacterial chemotherapy. Tests of this kind, which might well be described as prophylactic tests, are usually conducted in the following way. Groups of animals, often mice, are injected parenterally, usually intraperitoneally, with a number of lethal doses of the pathogen, and are divided into groups. The treated groups are given the drug, usually immediately and continued at short intervals for a shorter or longer time, and the assessment of worth is usually based on survival time or a similar parameter.

Provided the principles of biological assay are respected, and notably the inclusion of a control group, infected but untreated with drug, and the simultaneous inclusion of an active substance as a standard of comparison, the method may be reliable and capable of statistical appreciation.

May we remind ourselves that simple tests of this kind facilitated the discovery of prontosil rubrum, sulphanilamide and the substituted sulo phonamides, streptomycin and the newer anti- 흘. biotics, and remain today the basis of screenings tests for gram-positive and some gram-negative organisms. Indeed, in one form or another this simple test was used as the starting place for theadvancement of most chemotherapeutic substances known to us.

The test organisms included are very variable among both gram-positive and gram-negative ore ganisms. It should be noted that the design of the test requires an overwhelming infection which is suppressed during the course of the drug adw ministration, and for a short time thereafter; for if the survivors are kept they invariably succumb to a delayed bacteraemia.

Experiments in which Toxins are Produced

In contrast we must now look at experiments్s made with micro-organisms which produce one os more diffusible toxins. Should the infecting or $-\overrightarrow{-}$ ganisms be drawn from a heterogeneous grogp which produce diffusible toxins, e.g. Cl. tetani, $\ell_{l}^{N}$ botulinum, $\mathrm{Cl}$. Welchii or $\mathrm{N}$. diphtheriae, gaํ맘 organisms susceptible to sulphonamides, then thes test is likely to fail, even on a prophylactic levelo unless special precautions are taken. Thus, के satisfactory comparison of the 'gas-gangrene $\stackrel{\mathbb{D}}{2}$ clostridia may be made, provided the infecting organisms are first washed free from toxins. It is interesting and significant that the spores lie dormant in the apparently healthy tissue of animals? which have recovered from the primary lesion and may be reactivated at a later period by the in 3 . jection of necrotising agents such as sterile quartis or calcium chloride solution.

At least two biochemical lesions are involved the first, the bacteriaemia of numbers of or ganisms or the non-diffusible somatic toxin, and the second, the specific biochemical lesion of thes toxin itself. There is usually more than one of the latter. The animal test here is a faithful mirror of clinical experience with chemotherapy against these causal pathogens.

\section{Experiments in which Numerous Bio- chemical Lesions are Produced. Acid-Fage Organisms}

Let us now turn to tests in which acid-fact bacteria are used and which produce a number of pharmacologically active substances. At once \& major difference is met. Instead of an acute ex 
periment of a few days' duration based on an overwhelming infection, we must resort to a chronic infection of some weeks' duration based upon an admittedly large number of organisms.

In a simple test with mice it is usually essential to inject a large number of viable organisms intravenously to ensure the death of all animals within a group in the short period of time of 30 days. With guinea-pigs, injection of a large number of organisms is usually made subcutaneously, and the test is of a number of weeks' duration. More recently tests in dogs and monkeys infected intratracheally or intranasally have been described by Francis, Spinks and Stewart (1950). The latter tests have arisen from an appreciation of the peculiar pathogenesis of the disease. However, all tests illustrate the same principle, namely, the genesis of a number of biochemical lesions associated with "the pathology of the disease, and which modify its course. Thus, instead of a bacteraemia we have a characteristic lesion arising as a direct result of multiplication of the parasite - the tubercle. Associated are a number of biochemical lesions, discussed elsewhere (Brownlee, 1948), which may be listed.

\section{The Biochemical Lesions which Follow In- vasion by a Tubercle Bacillus}

I. Multiplication of the parasite.

2. Chemiotaxis of monocytes.

3. Inhibition of proteases.

4. Hypersensitivity effect.

5. Skin allergy.

6. Acauired resistance.

Specific antimicrobial chemotherapy is associated only with the first, and even this is quickly modified to create the limitations associated with the use of our currently used chemotherapeutic agents. We may now accept the hypothesis that some disease processes, e.g., those caused by clostridia and tuberculosis, are unlikely to be dramatically modified beyond our present understanding by the discovery of a more efficient antibiotic. There are, however, some additional factors which pass comment on this thesis.

\section{The Factors which Influence the Effect of Chemotherapeutic Agents on a Bacterial Population.}

These may be listed as:

I. The efficiency of the agent.

2. The effect of numbers of organisms.

3. The rate of emergence of resistant strains.

Whether factors $I$ and 2 are related depends on the mode of action of the drug. For example, it is agreed (Henry and Hobby, I949), that streptomycin is predominantly bacteriostatic, although it may be shown to be bactericidal under certain conditions. Unlike penicillin, the activity of streptomycin varies with the concentration, the size of the inoculum, the medium and the $\mathrm{pH}$. Streptomycin is most effective against dividing cells, but may have some effect against resting organisms.

A present-day limitation to the unrestricted use of streptomycin in chemotherapy is the frequency and rapidity with which resistant strains emerge from initially sensitive strains. This is found also with test-tube experiments. In contrast, the emergence of resistant strains to penicillin is low. The streptomycin resistance ranges from cells only slightly more resistant than the original to absolute resistance (Demerec, 1945); with penicillin the range is narrow.

Test tube experiments show two patterns of development of resistance. Resistance develops in one pattern, characteristic of penicillin, only in a slow, step-wise manner during serial transfer in progressive concentrations of the antibiotic. In the second pattern, characteristic of streptomycin, a high degree of resistance may develop after comparatively few exposures or possibly after even a single exposure to the antibiotic (Miller and Bohnhoff, 1946).

\section{Mechanism of Action of Emergence of Resistance}

The statistical method of Lauria and Delbrück (1943) has provided acceptable evidence for the mutation theory. In brief, it is believed that in any large population of bacteria there exists, albeit in relative small numbers, mutants capable of surviving and growing in otherwise bactericidal conditions. In criticism one must acknowledge variables other than mutation to be included in the statistical population. On the other hand, those who are critical of the adaptation theory, point to the existance of strains resistant to concentrations of antibiotics greater than that in which they have been trained. (See, for example, the experiments of Silver and Kempe, 1947; Demerec, 1945; Linz, 1948.) A recent discussion by Barer (I95I) is of interest, and for the present the subject must still be considered to be under discussion.

\section{The Logical Use of Combined Therapy}

The inability of micro-organisms to grow in a given concentration of an antibiotic involves the selection (elimination) of those cells unable to survive in that concentration. The survivors are the progenitors of the ultimate resistant population. Other antibiotics, antibacterial by reason of a different mode of action, may be logically used to eliminate the susceptible fraction of the emergent population. In theory, as many agents as there are mutants may be used. In practice, two or three 
drugs are used simultaneously. The practical problem resolves itself into bridging the desired period of treatment without emergence of a resistant strain to any one drug.

Combinations must, however, be justified by results. Diminution in efficiency may be met when two agents are combined. This is possibly true of the combination of aureomycin with penicillin, which in laboratory experiments (Gunnison, Coleman and Jawitz, 1950) is less effective than when used singly. It appears that the bacteriostatic action of aureomycin inhibits the metabolic processes of growth with which penicillin interferes. From our knowledge of the similarity of action of aureomycin, chloramphenicol and terramycin, the latter two drugs might be expected to behave in a similar way.

\section{Classification of Antibiotics}

From the basis of this review we are now in a position to consider four groups of antibiotics which fill the present scene.

Penicillin has been called an ideal chemotherapeutic agent. It is a weak acid whose salts are soluble, are rapidly excreted and are without toxicity. It has been studied most and we may soon expect to know something of its mode of action (Brownlee, 195I). Mycomycin, a new antimycobacterial substance, also a weak acid, is a potential candidate for this group.

A second but basic group, also derived like penicillin from fungi, includes streptomycin (and streptothricin), neomycin and viomycin. These antibiotics are stable, soluble in water and insoluble in organic solvents. These substances are toxic but useful. A beginning has been made with mode of action studies of streptomycin.

A third group comprises those extracted from bacteria. They are basic polypeptides of high molecular weight. Even when purified by exacting and meticulous physico-chemical tricks, they are usually mixtures of closely related substances. They are thermostable, diffuse slowly, adsorb readily and are absorbed and excreted slowly. Some are quite toxic; some, like polymyxin B and $\mathrm{E}$ are not. Included are the polymyxins, gramicidin, subtilin, circulin, bacitracin and licheniformin. Nothing is known of their mechanism of action.

In a final group may be included antibiotics which show antirickettsial activity. Aureomycin and terramycin may prove to be similar chemically. Both are amphoteric substances reacting with acids and bases to form soluble salts. Chloramphenicol is a neutral substance. The mode of action of this group is unknown.

\section{The Most Recent Antibiotic Agents}

The rapid rate of excretion of penicillin necessitates frequent injections, and alternative devices have been sought to maintain tissue con centrations. These include (a) the use of ver large doses, (b) the use of mechanisms to delay absorption, and (c) the use of drugs to minimize kidney ercretion. Mechanism.(c) is related to the fact that 80 per cent. of urinary penicillin is ex creted by the tubules (Rake and Richardson, 1946 By simultaneously giving large doses of drugs which are also excreted by the tubules, penicillin excretion is delayed by competition. Examples of this largely theoretical use are diodone (Rammel kamp and Bradley, 1943), p-aminohippuric acid (Beyer et al., 1947), and sodium benzoate.(Spauld ing et al., 1947). Beyer et al. (1947) ascribed ads vantages to 'Caronamide' (carboxyphenylmetho anesulphonanilide) which reversibly blocks ex cretion of penicillin, it is believed by enzymic in hibition, although itself excreted - slowly onlye through the glomeruli. The most useful exampled of mechanism (b) proved to be the use of procain $\vec{b}$ penicillin, which retains sufficient of its local anaesthetic properties to be painless on injection? It has the disadvantage that it inhibits the action of sulphonamide drugs by reason of its procain content. For a newcomer, dibenzylethylenedê amine penicillin (Elias, Price and Merrion, 195 I is claimed the advantages of better durations concentration time than procaine penicillin, and that repeated doses gives cumulative effects. 흑 has the same anaesthetic potency but is slightl more toxic. For an ester of penicillin markete under the trade name of 'Estopen' is claimed thë advantage of excretion into the sputum in high concentrations. Preliminary experiences are saigt to be encouraging.

\section{Streptomycin and Dihydrostreptomycin}

Danger of temporary or permanent damage to the eighth cranial nerve, resulting in vestibular. dysfunction, is in direct ratio to the dose and duration of streptomycin treatment. The hope. that this danger might be minimized by the use of dihydrostreptomycin has not been sustained. follows from the earlier discussion that we map confidently expect the development of additiona antibiotics with advantages over streptomycin an its reduction product. These would includes bactericidal rather than bacteriostatic action, in susceptibility to the effects of numbers of or ganisms, and a minimal rate of emergence o⿱ resistant strains.

Neomycin. Neomycin is a product of Strepto myces fradiae. It has antitubercular action in th\$ test tube, including streptomycin resistant strains (Waksman and Lechevalier, r949). It is alsg chemotherapeutic in the tubercle bacilli infected animal (Carr, Pfuetze, Brown, Douglas ancep 
Karlson, 195 I). Serious toxic effects, the principal of which are renal damage and deafness, which is progressive after administration is stopped, are observed. Unless these prove to be due to impurities which can be eliminated the antibiotic is unlikely to survive clinical trial.

Viomycin. Isolated from Streptomyces floridae or puniceus in two different laboratories in 1950, it is antibacterial in vitro against Myco. tuberculosis with little or no other antibacterial activity. In the experimental animal its chemotherapeutic efficiency is little different from that of streptomycin. It causes renal damage and vestibular damage, and also partial deafness. Changes in electrolyte balance with a fall in plasma potassium, calcium, phosphorus and chlorides and an increase in $\mathrm{CO}_{2}$ combining power of the blood have been recorded. It has been pressed into service against streptomycin-resistant tubercle bacilli (Finlay et al., 195I).

The polymyxins. The name polymyxin applies not to one substance but to a group of five closely related polypeptide antibiotics derived from five different strains of Bacillus polymyxa. Polymyxin A was originally known as 'Aerosporin' and was shown to be nephrotoxic in animals by Brownlee and Bushby (1948). Polymyxin D is the original polymyxin described by Stansley et al. (1947), and was shown to be similarly nephrotoxic in animals (Bryer et al., 1949; Brownlee et al., 1949; Schoenbach et al., 1949). A third nephrotoxic member of the series, polymyxin $\mathrm{C}$, has also been reported (Brownlee et al., 1952). Although the renal damage caused by these polymyxins was transitory and limited to the convoluted tubules it was sufficient to restrict their use, and a fuller clinical assessment could not be made until this renal toxicity had been overcome. Polymyxin B was reported by Brownlee et al. (1949) to be virtually free from this toxicity, but to cause pyrexia, neurotoxic signs and severe reactions at the site of injection in animals. Polymyxin $\mathrm{E}$, the most recent of this group, does not cause pyrexia or local reactions in animals and is almost free from the renal toxicity displayed by polymyxins $A, D$ and $C$ (Brownlee et al., 1952). Apart from these pharmacological differences the polymyxins are similar. They have almost identical antibacterial activities in vitro, being specifically active against the gramnegative bacilli, and all containing approximately 10,000 polymyxin A units per mg. Their action is bactericidal and it is only with difficulty that resistant strains can be made to emerge from repeated sub-culture. The minimal inhibitory concentration depends on the number of organisms present. Experimentally the polymyxins have some advantages over streptomycin. They appear to be the most effective agents known to us against
Haemophylus pertussis, $H$. influenzae and Pseudomonas pyocyanea. Although streptomycin is also bactericidal, its intrinsic activity is less than that of the polymyxins (Alexander et al., 1950); streptomycin is active in concentrations of roug. per $\mathrm{ml}$., whereas polymyxin is active at $\mathrm{I}$ to ro $\mu \mathrm{g}$. per ml. Brownlee and Bushby (1948) showed that the in vitro strain $\mathrm{CN} 25^{8}$ of $H$. influenzae was inhibited by $0.02 \mu \mathrm{g}$. per ml. of polymyxin A compared with I $\mu \mathrm{g}$. per ml. of streptomycin, and in mice infections roo $\mu \mathrm{g}$. of polymyxin A gave the same protection as $1,250 \mu \mathrm{g}$. of streptomycin. Streptomycin readily permits resistant organisms to develop, but with the polymyxins resistant strains are produced in vitro only with the greatest difficulty. In human cases of $H$. influenzae infection treated with polymyxin there has not been any tendency for resistant strains to develop (Alexander et al., 1949).

Alexander and her colleagues (1949) compared the in vitro activities of aureomycin and chloramphenicol with that of polymyxin B. They found the minimal effective concentrations required to prevent growth of $H$. influenzae in vitro to be: Streptomycin, I to $3 \mu \mathrm{g}$. per $\mathrm{ml}$.; polymyxin B, $0.3 \mu \mathrm{g}$. per ml.; chloramphenicol, I $\mu \mathrm{g}$. per ml.; and aureomycin, 0.5 to $1.0 \mu \mathrm{g}$. per $\mathrm{ml}$.

Chandler and Hodes (1950) compared the therapeutic effect of streptomycin, dihydrostreptomycin, polymixin and aureomycin in $H$. influenza type $B$ infections in mice. At high doses there was little to choose between the antibiotics, but at low doses prlymyxin B was much the best.

Swift and Bushby (195I) successfully treated eight children intrathecally and intramuscularly with polymyxin B (one) and polymyxin $\mathrm{E}$ (seven) suffering from $H$. influenzae meningitis. Brakley (1950) reported the successful treatment of a severe case of $H$. influenzae meningitis with polymyxin B, and Hayes and Yow (1950) have demonstrated its value in meningitis caused by $P$ s. pyocyanea. In view of the interest being taken in the antivirus poteritial of antibiotics, the antiphage activity of polymyxin $B$ is of interest. Of 45 substances of known antibacterial activity which were tested against 6o races of bacteriophage, using paper disc methods, only eight showed antiphage activity, and only polymyxin B showed good activity. Against one it proved active at a concentration of $10 \mathrm{mg}$. per ml. (Hall, Kavanagh and Asheshov, 1951). Subtilin, which was included in this test, appears to have comparable phage and virus activity, since it is claimed to be capable of inactivating influenza A virus (Salle, r950).

Aureomycin, Chloramphenicol and Terramycin

These three antibiotics have established for 
themselves a place in medicine not only for their catholic antibacterial spectrum but by breaking new ground with antivirus and anti-rickettsial activity. They are essentially similar and include in their fields of action gram-negative and grampositive pathogens. They therefore find a natural outlet against penicillin-resistant and streptomycin-resistant organisms. Current research is concerned with establishing the particular sphere of each, and we will concern ourselves only with special aspects.

The simultaneous increase in resistance of bacteria. The simultaneous and parallel increase in resistance of organisms to aureomycin, terramycin and chloramphenicol on exposure to each antibiotic in vitro and in vivo has been commented on by different groups of workers (Herrell, Heilman and Wellman, 1950). Terramycin appears to have the advantage of a pattern of microbial resistance characteristic of penicillin in contrast to that of streptomycin (Hobby, Lenert, Donikian and Pikula, 1951). Terramycin appears to be establishing a special use in syphilis. Unlike aureomycin and chloramphenicol, it resembles the activity of penicillin in healing the scrotal syphilomas caused by Treponema pallidum in rabbits (Levaditi and Vaisman, 195I). Terramycin has been described by Loughlin and Joseph (I95I) as the most effective antibiotic yet studied in yaws and tropical ulcer. Aureomycin had been found of value in the treatment of amoebic dysentery. Clinical improvement with 85 per cent. cures, with disappearance of amoebae, being reported by Siguier and Choubrac (I95I). Hepatic amoebiasis was unaffected. A sober and valuable assessment by Ley et al. (r95I) observed clinical control in 12 of 12 patients with re- appearance of the amoeba in three of eight patien who were followed up. The same authors draw attention to similar results observed by Armstron Wilmot and Elsdon-Dow (1950), who are in 9 peculiarly favourable position to judge by reaso of their past experiences and trials.

Chloramphenicol. This antibiotic retains i preferred position in rickettsial infections. In trial in scrub typhus the order of efficiency wass chloramphenicol, aureomycin, terramycin and para-aminobenzoic acid (Bailey, Ley, Diercks. Lewthwaite and Smadel, I95I).

\section{Summary}

I. A historical review enables the identificatio of certain principles which appear to have im fluenced the development of antibiotics and the selection for clinical application.

2. By projecting these principles, in a gener丝 way, into the future, it appears possible to indicate lines of development.

3. 'I'he peculiar pathogenesis of certain disease caused by parasites susceptible to chemotherapy limits the application of antibiotics and thus in fluences their development.

4. The discovery of new antibiotics effectiv against viruses, the gram-negative rods and protozoa may be foreseen.

5. The replacement of inefficient antibioticsis more efficient members is inevitable. The quirements include bactericidal rather than bas teriostatic action, insusceptibility to the effect of numbers of organisms and a minimal rate emergence of resistant strains.

6. The most recent antibiotics are discussez and some facets of their development and applicas tion explored.

\section{BIBLIOGRAPHY}

ALEXANDER, H. E. (1947), Adv. Pediat., 2, 121.

ALEXANDER, H. E., LEIDY, G., and REDMAN, W. (1949), 7. clin. Invest., $28,867$.

BARER, G. R. (1951), F. Gen. Microbiol., 5, r.

BEYER, K. H., RUSSO, H. F., PATCH, E. A., TILLSON, E. K., and SHAVER, G. (1947), $\mathcal{F}$. Pharmacol., 91, 272.

BRAKLEY, E. (1950), $\mathfrak{f}$. Pediat., 37, 42.

BROWNLEE, G. (1951), Ann. Rev. Microbiol., 5, 197.

BROWNLEE, G., and BUSHBY, S. R. M. (1948), Lancet, i, 127.

BROWNLEE, G., BUSHBY, S. R. M., and SHORT, E. I., (1949), Ann. N.Y. Acad. Sci., 5I, 952.

BROWNLEE, G., BUSHBY, S. R. M., and SHORT, E. I. (1949). Brit. F. Pharmacol., March 1952 (in press).

BRYER, M. S., SCHOENBACH, E. B., and BLISS, E. A. (1949),-Ann. N.Y. Acad. Sci., 51, 935.

CHAIN, E., FLOREY, H. W., GARDNER, A. D., HEATLEY, N. G., JENNINGS, M. A., ORR-EWINGS, J., and SÁNDËRS, A. G. (1940), Lancet, ii, 226.

CARR, D. T., PFUETZE, K. H., BROWN, H. A., DOUGLAS, B. E., and KARLSON, A. G. (1951), Amer. Rev. Tuberc,, 63, 427.

CHANDLER, C. A., and HODES, H. L. (1950), Pediatrics, 5, 267. COLEBROOK, L., and KENNY, M. (1936), Lancet, ii, 1319. DEMEREC, M. (1945), Proc. Nat. Acad. Sci. Wash., 31, 16.

DOMAGK, G. (1935), Deutsch. Med. Wschr., 61, 829.
ELIAS, W., PRICE, A. H., and MERRION, H. J. (195羿; Antibiotics and Chemotherapy, $\mathrm{I}, 49 \mathrm{I}$.

FINLAY, A. C., HOBBY, G. L., HOCHSTEIN, F., LEES T. M., LENERT, T. F., MEANS, J.A., P'AN, S.'Y., REGNA P. P., ROUTIEN, J. B., SOBIN, B. A., TA'TE, K. B., ara
KANE, J. H. (1951), Amer. Rev. Tuberc., 63, I.

FLEMING, A. (1929), Brit. F. exp. Path., 10, 226.

FRANCIS, J., SPINKS, A., and STEWART, G. T. (1950), Bri 7. Pharmacol., 5, 549 .

HALL, E. H., KAVANAGH, F., and ASHESHOV, I. N. (195 Antibiotics and Chemotherapy, I, 369.

HAYES, E. R., and YOW, E. (1950), Amer. F. Med. Sci., 220, 6313 HENRY, R. J., and HOBBY, G. L. (1949), ' Streptomycin, NatưPe and Practical Applications,' S. J. Waksman, Williams Wilkins Baltimore.

KIKUTH, W. (1932), Deutsch. med. Wschr., 58, 530.

LINZ, R. (1948), Compt. rend. Soc. Biol., 142, 1066.

MILLER, C. P., and BOHNHOFF, M. (1946), f.A.M.A., 130, 48 RAKE, G., and RICHARDSON, A. P. (1946), Ann. N.Y. Acad Sci., 48, 143 .

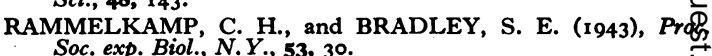

SALLE, A. J. (1950), ' Bacteriological Proceedings,' p. 72, M. 8. SCHOENBACH, E. B., BRYER, M. S., and LONG, P. H. (r94@) Ann. N.Y. Acad. Sci., 51, 987.

(Continued on page 157) 


\section{ANNOTATION}

\section{The Bone Bank}

In many centres in this country a 'bone bank' is becoming a standard part of the facilities of an orthopaedic department. The development of this service has taken place mainly in the United States, particularly by P. D. Wilson (195I).

Bone grafting is an everyday procedure where sound and rapid bone healing is required. Bone taken from the patient-an autogenous graft-has no blood supply, and all the cells must die, except perhaps those on the very surface. Its use is to give mechanical stability while new bone is formed in and around the graft, which itself becomes incorporated and replaced. This is the same process which takes place when the small fragments of a comminuted fracture become embedded in a mass of callus as the fracture heals.

Experimental work would suggest that a homogenous graft (from another patient) differs from an autogenous graft only in the invariable death of the surface, as well as of the deep cells. This seems to be unimportant, and the final results are equally satisfactory whichever type of graft is used. Thin slices of cancellous bone probably survive complete as living entities and such grafts laid, for instance, on a skull defect become clinically sound within three weeks.

The bone bank consists of a deep-freeze refrigerator kept at a constant temperature of $-20^{\circ} \mathrm{C}$. The bone is usually from the rib of a young patient undergoing thoracotomy for a non-infective condition, a Wassermann reaction being taken before the bone is used. The rib taken at operation is placed in a sterile screw-topped jar containing normal saline in which is dissolved penicillin (ro,000 units) and streptomycin (I0,000 micrograms). Most authorities credit this procedure as being satisfactory in preserving homogenous grafts for at least four months.

Recently, Kreuz, et al. (I95I), have used bone which has been freeze-dried by the technique suggested by Flosdorf (1949) and then stored at room temperature. This technique is particularly suitable for isolated units where a suitable refrigerator is not available. It has been suggested that this technique should be used under war-timg conditions.

\section{BIBLIOGRAPHY}

FLOSDORF, E. W. (1949), 'Freeze Drying by Sublimation,' Reinhold Publishing Corp., p. 138.

KREUZ, et al. (195I), 7. Bone Ұt. Surg., 33, 863. WILSON, P. D. (1951), Ibid., 33, 301.

\section{NOTE}

\section{NEW PRODUCT-'DIAMETHINE’}

Burroughs Wellcome \& Co. announce the introduction of 'Diamethine' brand injection of dimethyltubocurarine bromide, a muscle relaxant with an action similar to, but of slightly shorter duration than, $d$-tubocurarine chloride, and causing less histamine release. 'Diamethine' is the bromide salt of the dimethyl ether of $d$-tubocurarine, and is miscible in all proportions with intravenous barbiturates. Intended as a companion product to 'Tubarine' brand injection of $d$-tubocurarine chloride, it is issued in a strength ( $4 \mathrm{mgm}$. per c.c.) approximately equipotent in muscle-relaxing effect with ' Tubarine.' 'Diamethine' is available as ampoules containing $6 \mathrm{mgm}$. in 1.5 c.c. (box of $6,2 \mathrm{ss}$. 6d.; 25, 83s. 6d., subject) and rubber-capped bottles of $20 \mathrm{mgm}$. in 5 c.c. (ros. 9d. each, subject).

\section{(Continued from page 144$)$}

SILVER, H. K., and KEMPE, G. H. (I947), F. Immunol., 57, 263. SPAULDING, E. H., BONDI, A., and EARLY, F. (1947), F. Lab. clin. Med., 32, 807.

SWIFT, P. N., and BUSHBY, S. R. M. (1951), Lancet, ii, 183.

WAKSMAN, S. H., and LECHEVALIER, H. A. (1949), Science. I09, 305 .

Aureomycin, Chloramphenicol and Terramycin:

ARMSTRONG, T. G., WILMOT, A. J., ELSDON-DEW, R. (1950), Lancet, ii, 10.

BAILEY, C. A., LEY, H. L., DEERCKS, F. H., LEWTHWAITE, R., and SMADEL, J. E. (1951), Antibiotics and Chemotherapy, I, 16 .
HERREL, W. E., HEILMAN, F. R., and WELLMAN, E. E. Ann. N.Y. Acad. Sci., 53, 448.

HOBBY, G. L., LENERT, T. F., DONIKIAN, M., and PIKULA, D. (1951), Amer. Rev. Tuberc., 63, 434 .

LEVADITI, C., and VAISMAN, A. (195i), Chemotherapy and Antibiotics, 1, 425.

LEY, H. L., SAYER, W. J., HOBSON, A. C. S., VANREENEN, R. M., TIPTON, v. J., FRICK, L. P., BÄLLARD, E. L., TRAUB, R. (195I), Antibiotics and Chemotherapy, 1, 281.

LOUGHLIN, E. H., and JOSEPH, A. A. (195I), Ibid., x, 76.

SIGUIER, F., and CHOUBRAC, M. (195I), Bull. Soc. méd, Hop. de Paris 67, 217. 